\title{
OPTIMIZATION OF PROCESS PARAMETERS OF ELECTRIC DISCHARGE MACHINING OF EN44 TOOL STEEL FOR MAKING CIRCULAR HOLE
}

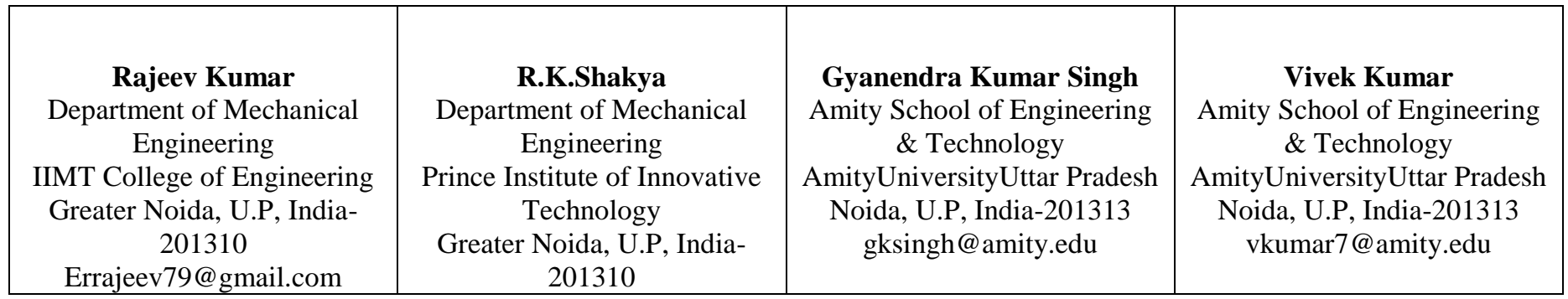

\begin{abstract}
This paper presents an experimental investigation of Electro Discharge Machining (EDM) of EN44 tool steel for making circular hole. Nine samples of work-piece material (EN44 tool steel) were drilled by copper drill using electric discharge drilling process. Current, Pulse on time (Ton), Pulse off time (Toff), and drill diameter are taken as input parameters and material removal rate (MRR) and tool wear rate (TWR) as output parameters. The results have revealed that drill diameter is the most influencing parameters for MRR and TWR. Taguchi methodology was used for optimization of MRR and TWR. L9 orthogonal array (OA) has been used to design the experiment. Keywords - EDM, MRR; TWR; S/N ratio; Optimization.
\end{abstract}

\section{INTRODUCTION}

In the last few years, EDM has become a key non-traditional manufacturing process, widely used in several industrial sectors including aerospace and automotive. EDM allows to obtain precise, complex and irregular shapes with high accuracy and fine resultant surface finish on materials which are considered difficult-to-machine through traditional processes. Currently, it is used to machine a wide variety of electrically conductive materials from metals, alloys, sintered materials, cemented carbides, etc. However, the achievement of zero-defect EDM manufacturing still represents a challenge, even with skilled operators and state-of-the-art CNC machines, mainly due to the large number of variables and the stochastic nature of the process mechanisms involved. The working principle of EDM is shown in fig. 1. In this operation, the material removal occurs from any electrically conductive material by the initiation of rapid and repetitive spark discharges between the gaps of work piece and tool electrode connected in an electrical circuit. A liquid dielectric medium is continuously passed in the gap provided between the wire and work piece.

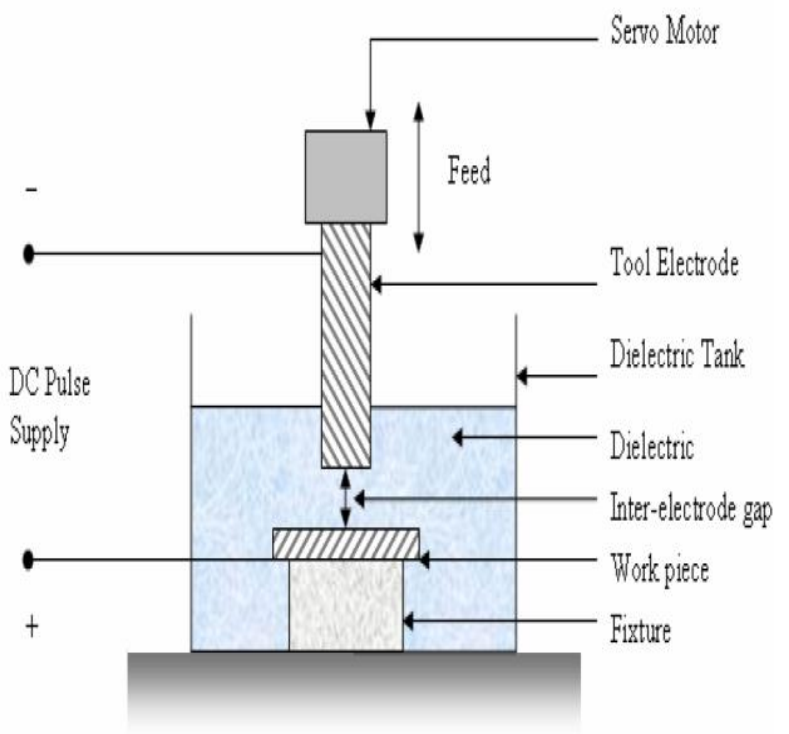

Fig. 1. Schematic representation of Die Sinking EDM Process

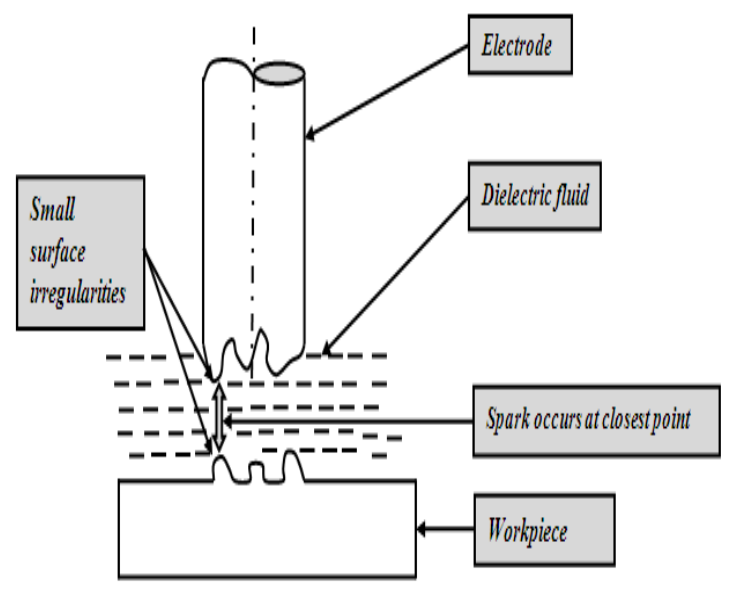

Fig.2. Working principle of EDM 
A thin gap about $0.025 \mathrm{~mm}$ is maintained between the tool and work piece by a servo system. Both tool and work piece are submerged in a dielectric fluid. Kerosene/EDM oil/de-ionized water is very common type of liquid dielectric although gaseous dielectrics are also used in certain cases. The tool is made cathode and work piece is anode. When the voltage across the gap becomes sufficiently high it discharges through the gap in the form of the spark in interval of 10 microseconds. And positive ions and electrons are accelerated, producing a discharge channel that becomes conductive. It is just at this point when the spark jumps causing collisions between ions and electrons and creating a channel of plasma. A sudden drop of the electric resistance of the previous channel allows that current density reaches very high values producing an increase of ionization and the creation of a powerful magnetic field. The moment spark occurs sufficiently pressure developed between work and tool as a result of which a very high temperature is reached and at such high pressure and temperature that some metal is melted and eroded. Such localized extreme rise in temperature leads to material removal. Material removal occurs due to instant vaporization of the material as well as due to melting. The molten metal is not removed completely but only partially. Most manufacturing technologies in micro systems technology are derived from semiconductor industry.

Machining by milling is limited to materials with a degree of hardness smaller than $62 \mathrm{HRC}$. Hence, ablating processes gain more and more importance in micro manufacturing. EDM (electrical discharge machining) Machining and laser ablation are both suitable for a non-contact Machining process and thus a material removal without any process forces-irrespective of mechanical material properties, such as hardness or strength. A classical field of application is the mould and die production since these processes can realize smallest structures in high-strength, hardened materials and therefore mostly wear-resistant materials. Here, combined and single manufacturing technologies are utilized, e.g. wire-electrical discharge machining to fabricate shaped electrodes for diesinking EDM and laser ablation for cutting and drilling or to fabricate cavities [1]. EDM is mainly used to machine difficult-to-machine materials and high strength temperature resistant alloys. EDM can be used to machine difficult geometries in small batches or even on job-shop basis. Work material to be machined by EDM has to be electrically conductive [2].

\section{LITRATURE REVIEW}

This section deals with the research carried out by various researchers on different aspects of EDM process. M. K. Pradhan et al. [3] optimised the various machining parameters for the EDM processes on American Iron and Steel Institute (AISI) D2 tool steel using Commercial grade EDM oil as dielectric Fluid with a hybrid optimisation method. Response surface methodology (RSM) and grey relational analysis (GRA) approach was used to optimise parameters for electrical discharge machining process. It was reported that by setting the optimum parameters, the desired material removal rate (MRR) and minimum TWR for EDM die sinking of (AISI) D2 tool steel can be achieved. Similarly S. Singh et al. [4] used the grey relational analysis (GRA) approach to optimise parameters for electrical discharge machining process of $6061 \mathrm{Al} / \mathrm{Al}_{2} \mathrm{O}_{3} \mathrm{p} / 20 \mathrm{P}$ aluminium metal matrix composites for maximum MRR, minimum TWR and minimum surface roughness (SR). In this work an L18 $\left(2^{\wedge} 1 \times 3^{\wedge} 5\right)$ orthogonal array is taken to determine an optimal setting. Optimum values of the process parameters (The process parameters included one noise factor, aspect ratio having two levels and five control factors, viz. Pulse current, pulse ON time, duty cycle, gap voltage and tool electrode lift time with three levels each.) were determined after analyzing the experimental results using the grey relational and statistical analysis of variance (ANOVA). Experimental results have shown clearly that the material removal rate, tool wear rate and surface roughness in the EDM process can be improved effectively through the proposed approach analysis. Paul et al. [5] carried out a research to find out influence of process variables and optimal conditions for minimum overcut on crater dimensions using $\mathrm{L}_{9}$ orthogonal array and analysis ANOVA test. Authors investigated the effect of different dielectric mediums in microEDM machining of $\gamma$-titanium aluminide alloy (Ti-44.5 Al-2 $\mathrm{Cr}-2 \mathrm{Nb}-0.3 \mathrm{~B}$ in \%). Experiments were conducted both in the absence (dry conditions) and in presence dielectric medium (EDM oil). It was observed that for given micro-EDM process parameters, the crater depth formation by a single discharge in the absence of dielectric liquid (dry micro-EDM) is relatively small, compared to machining in presence of dielectric oil. Payal et al. [6] studied the surface characteristics of Electrical Discharge machining of EN 31 tool steel with copper, brass \& graphite as tool electrode with kerosene oil as dielectric fluid. Experiments were performed to determine parameters affecting surface roughness along with structural analysis of surfaces with respect to material removal parameters. Optimum EDM machining parameters for maximum MRR, minimum TWR performed experiments on Nimonic75 super alloy using Taguchi's orthogonal array $\mathrm{L}_{18}$ using a rotary attachment to hold the copper disk electrode. This increases the electrical discharges, facilitating in the improvement in material removal and better surface finish. Peak current and aspect ratio are the main significant factors responsible for increase in MRR and decrease in disk electrode wear rate and surface roughness (SR). The EDM process parameters were optimized for material removal rate, disk electrode wear rate, and surface roughness. Pushpendra et al. [7] performed experiments on diesinking EDM by taking Inconel 718 as work piece and copper as tool electrode to optimize the EDM process parameters (In this research work, L 36 orthogonal array is taken for experiment design. Shape factor (SF), Pulse-on-time (Ton),

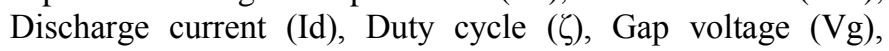
Flushing pressure $(\mathrm{P})$ \& Tool electrode lift time are taken as input parameters.). In this research Genetic algorithm has been proven as one of the most popular multi-objective optimization techniques for the parametric optimization of EDM process. Artificial neural network forms an alternative approach to model the system efficiently as it is capable of mapping input variable and performance measures of EDM. Simulation has 
been performed in MAT Lab. ANN has been trained with the experimental data set. Controlled elitist non-dominated sorting genetic algorithm has been employed in the trained network and a set of pareto-optimal solutions is obtained. Bhattacharya et al. [8] carried out research to investigate the appropriate parameter settings for rough and finish machined surface for EN31, H11, and high carbon high chromium die steel materials in a powder-mixed electric discharge machining process. The

TABLE I. CHEMICAL COMPOSITION OF ELECTRODES (BOTH WORK-PIECE AND TOOL ELECTRODES)

\begin{tabular}{|c|c|c|c|c|c|c|c|c|c|}
\hline $\begin{array}{l}\text { Elements (work- } \\
\text { piece : EN44 } \\
\text { tool steel ) }\end{array}$ & $\mathrm{C}$ & $\mathrm{Si}$ & Mn & $\mathrm{S}$ & $\mathrm{P}$ & $\mathrm{Ni}$ & $\mathrm{Cr}$ & $\begin{array}{l}\mathrm{M} \\
\mathrm{o}\end{array}$ & $\mathrm{V}$ \\
\hline \% Composition & 1.05 & $\begin{array}{l}0 . \\
26 \\
2\end{array}$ & $\begin{array}{l}0.4 \\
97\end{array}$ & $\begin{array}{l}0.0 \\
35\end{array}$ & $\begin{array}{l}0 . \\
05\end{array}$ & $\begin{array}{l}0 . \\
08 \\
3\end{array}$ & $\begin{array}{l}1 . \\
14\end{array}$ & $\begin{array}{l}0 . \\
0 \\
2\end{array}$ & $\begin{array}{l}0.0 \\
15\end{array}$ \\
\hline $\begin{array}{l}\text { Element (work- } \\
\text { piece ) }\end{array}$ & $\mathrm{Ti}$ & $\begin{array}{l}\mathrm{C} \\
\mathrm{o}\end{array}$ & $\mathrm{Pb}$ & $\mathrm{Zr}$ & $\mathrm{Al}$ & $\mathrm{Fe}$ & $\begin{array}{l}\mathrm{C} \\
\mathrm{u}\end{array}$ & $\begin{array}{l}\mathrm{N} \\
\mathrm{b}\end{array}$ & B \\
\hline \% Composition & $\begin{array}{l}0.00 \\
8\end{array}$ & $\begin{array}{l}<0 \\
.0 \\
1\end{array}$ & $\begin{array}{l}<0 . \\
01\end{array}$ & $\begin{array}{l}<0 . \\
00 \\
6\end{array}$ & $\begin{array}{l}0 . \\
01 \\
5\end{array}$ & $\begin{array}{l}96 \\
.7 \\
5\end{array}$ & $\begin{array}{l}0 . \\
05 \\
5\end{array}$ & $\begin{array}{l}0 . \\
0 \\
1 \\
3\end{array}$ & $\begin{array}{l}<0 . \\
00 \\
05\end{array}$ \\
\hline $\begin{array}{l}\text { Element (Tool } \\
\text { Electrode: } \\
\text { Copper, } \\
\text { Diameter }-4.0 \\
\text { mm, } 8.0 \quad \mathrm{~mm} \text {, } \\
\text { and } 12.0 \mathrm{~mm})\end{array}$ & $\mathrm{Cu}$ & $\begin{array}{l}\mathrm{M} \\
\mathrm{n}\end{array}$ & $\mathrm{S}$ & $\mathrm{P}$ & & & & & \\
\hline \% Composition & 99 & $\begin{array}{l}0 . \\
70\end{array}$ & $\begin{array}{l}0.2 \\
0\end{array}$ & $\begin{array}{l}0.1 \\
0\end{array}$ & & & & & \\
\hline
\end{tabular}

improvement of surface properties measured in terms of improved finish and increased micro hardness with $\mathrm{Si}, \mathrm{W}$ and graphite powders mixed in dielectric in powder mixed electric discharge machining (PMEDM) process were investigated. The powder mixed with dielectric and its concentration, current and pulse on time were identified as the significant factors affecting surface finish. MRR, TWR, and surface finish were measured after each trial and analyzed. Renjie et al. [9] used a steel-toothed wheel as the tool electrode to machine $\mathrm{SiC}$ ceramic using electric discharge milling. Three kinds of emulsion (Emulsion-1 was 95 wt. \% distilled water+5 wt. \% emulsified oil with 25 wt. \% anionic compound emulsifier and 75 wt. \% machine oil. Emulsion-2 was 95 wt. \% distilled water+5 wt. \% emulsified oil with 25 wt. \% ACE, 1 wt. \%OP10, and 74 wt. \% machine oil. And Emulsion-3 was 95 wt. \% distilled water +5 wt. $\%$ emulsified oil with $25 \mathrm{wt}$. \%ACE, 1 wt. $\% \mathrm{OP}-10,2$ wt. \% rosin, and 72 wt.\% machine oil.) were proposed as the dielectric for machining. The process performance such as the MRR and surface roughness have been investigated. Shorter pulse duration and pulse interval, higher peak voltage and peak current, and positive tool polarity are suitable for $\mathrm{ED}$ milling of the $\mathrm{SiC}$ ceramic.

\section{MATERIALS AND METHODS}

The whole experiment was performed on SPARKONIX25A. Experiments were carried out to investigate EDM parameters like current, Ton, Toff, and electrode diameter and their effects on MRR, and TWR. MRR was based on diameter of electrode made of copper used for making round hole up to full thickness of material and time taken in machining was made constant. The machining time was calculated by machine-generator-setting monitor and MRR was calculated in $\mathrm{gm} / \mathrm{min}$. Table 1 shows the chemical composition of electrodes. Nine pieces of EN 44 Tool steel were prepared with the help of power Hack-saw. Finishing of the work pieces was done by using grinding machine.

The dimensions of work piece is $70 \mathrm{~mm} \times 70 \mathrm{~mm} \times 7 \mathrm{~mm}$. EN 44 Tool steel was machined using copper tool.

Commercial grade EDM oil was used as dielectric fluid with a pressure of $0.5 \mathrm{kgf} / \mathrm{cm}^{2}$. All experiments were conducted with positive polarity of electrode.

\section{A. Taguchi Method}

Taguchi's philosophy is an efficient tool for the design of high quality manufacturing system; it is based on orthogonal array (OA) experiments, which provides much-reduced variance for the experiment with optimum setting of process control parameters. Taguchi suggests two different routes to carry out the complete analysis. First, the standard approach, where the results of a single run or the average of repetitive runs are processed through main effect and Analysis of variance (ANOVA) analysis (raw data analysis).The second approach which Taguchi strongly recommends for multiple runs is to use signal-to-noise ratio $(\mathrm{S} / \mathrm{N})$ for the same steps in the analysis. Taguchi method uses a statistical measure of performance called signal-to-noise ratio. By maximizing the $\mathrm{S} / \mathrm{N}$ ratio, the loss associated can be minimized. The $\mathrm{S} / \mathrm{N}$ ratio determines the most robust set of operating conditions from variation within the results. The $\mathrm{S} / \mathrm{N}$ ratio is treated as a response (transform of raw data) of the experiment. The $\mathrm{S} / \mathrm{N}$ ratio takes both the mean and the variability into account. The $\mathrm{S} / \mathrm{N}$ ratio is the ratio of the mean (signal) to the standard deviation (noise).

The standard S/N ratios generally used are as follows:

I. Higher- the- better (HB)

II. Lower- the- better (LB)

III. Nominal- is- best (NB)

There are two Signal-to-Noise ratios of common interest for optimization of Problems in this work.

\section{SMALLER-THE-BETTER:}

$\mathrm{S} / \mathrm{N}$ ratio $=-10 \log$ (mean of sum of squares of measured data) 


\section{LARGER -THE- BETTER:}

$\mathrm{S} / \mathrm{N}$ ratio $=-10 \log$ (mean of squares of reciprocal of measured data)

\section{NOMINAL - THE- BEST}

$\mathrm{S} / \mathrm{N}$ ratio $=-10 \log$ (square of mean/variance)

These S/N ratios are expressed on a decibel scale. We would use equation (3) if the objective is to reduce variability around a specific target, equation (2) if the system is optimized when the response is as large as possible, and equation (1) if the system is optimized when the response is as small as possible. Factor levels that maximize the appropriate $\mathrm{S} / \mathrm{N}$ ratio are optimal. The goal of this present work was to produce maximum MRR and minimum TWR by EDM process. Larger MRR values represent large amount of material removed from the workpiece and smaller TWR values represent small amount of material removed form tool.

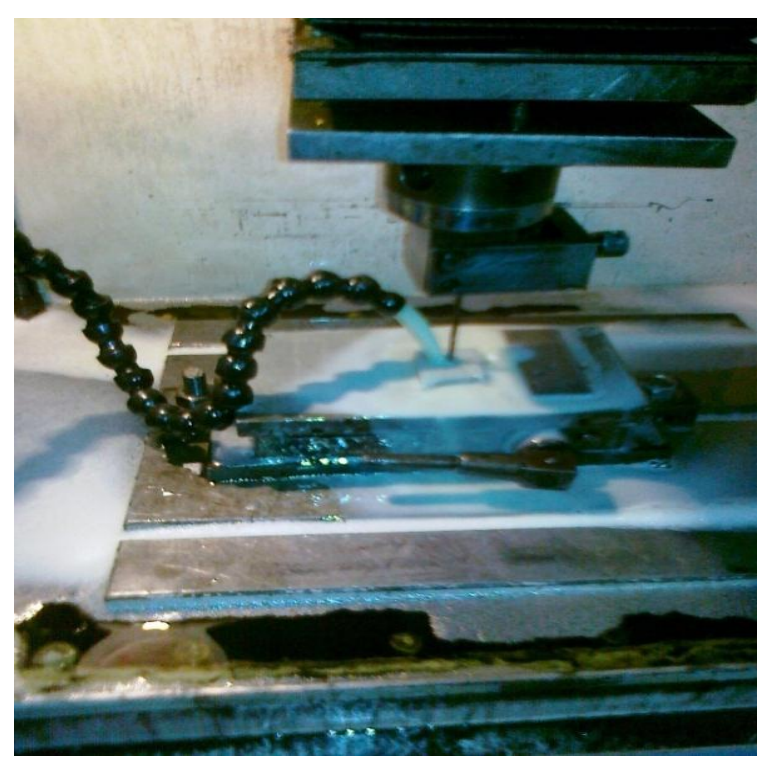

Fig.2 Tool holder with workpiece

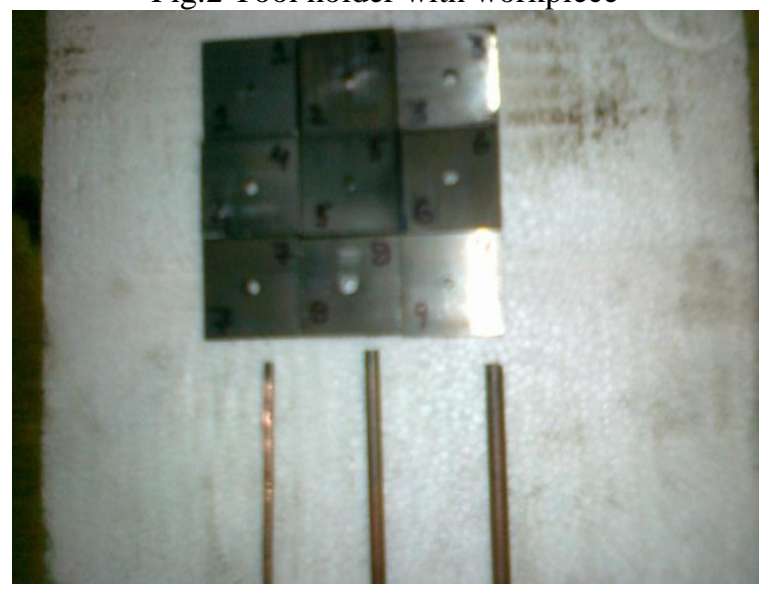

Fig.3 Machined workpieces with drilling tools

\section{B. Response Variable}

In this step, the process objectives need to be more specific, so that the experiments can be carried out properly. In order to achieve the process objectives, the method to evaluate those objectives must be taken into account so that no error is encountered which can lead to wrong conclusion of experiments. The objectives in this work optimize the response variables, which are MRR and TWR.

\section{TABLE II. MACHINING PARAMETERS \& ITS LEVEL VALUES}

\begin{tabular}{|l|l|l|l|c|c|c|}
\hline Factor & $\begin{array}{l}\text { Machining } \\
\text { parameters }\end{array}$ & Units & Symbol & $\begin{array}{l}\text { Level } \\
\mathbf{1}\end{array}$ & Level 2 & Level 3 \\
\hline A & $\begin{array}{l}\text { Pulse-on } \\
\text { time }\end{array}$ & $\mu \mathrm{s}$ & Ton & 3 & 6 & 9 \\
\hline $\mathrm{B}$ & $\begin{array}{l}\text { Pulse off } \\
\text { time }\end{array}$ & $\mu \mathrm{s}$ & Toff & 4 & 6 & 9 \\
\hline $\mathrm{C}$ & Current & $\mathrm{A}$ & $\mathrm{I}$ & 8 & 16 & 24 \\
\hline $\mathrm{D}$ & $\begin{array}{l}\text { Electrode } \\
\text { diameter }\end{array}$ & $\mathrm{mm}$ & $\mathrm{ED}$ & 6.23 & 9.10 & 12.30 \\
\hline
\end{tabular}

\section{Design Matrix and observation Table}

From the past studies and other researches done by others, it was decided that only four parameters will be taken into consideration. In this step, machining factors (parameters) are considered that influence the response of the system. In present case, the Die-Sinking EDM response has been studied. The experimental plan has four selected design factors current I (A), pulse on time Ton ( $\mu \mathrm{s})$, pulse off time Toff $(\mu \mathrm{s})$, and electrode diameter ED $(\mathrm{mm})$.

\section{Determine the number of level and the level value}

In this step, the number of level and its value is determined carefully. If curved or higher order polynomial relationship between the parameters under the study and the response is expected, at least three levels for each parameters should be considered. It is desirable to have three minimum level of the process parameters to reflect the true behavior of output parameters of study. Therefore, three levels of each parameter have been taken. The levels of the individual process parameters/factors are given in the table 2.

\section{EXPERIMENTAL RESULTS AND DATA ANALYSIS}

The experiment has 4 variables at 3 different settings. A full factorial experiment would require $3^{\wedge} 4=81$ experiments. We conducted an orthogonal array (9 tests, 4 variables, 3 levels). The experiment design is shown below.

\section{A. Effects of input factors on MRR and TWR}

After performing the statistical analysis on the experimental data, it has been observed that there is one particular level for each factor for which the response is either maximum (in case 
of MRR) or minimum (in case of TWR). The signal to noise ratio ( $\mathrm{S} / \mathrm{N}$ ratio) of each response corresponding to each factor level also has a maximum and a minimum value. So for finding the optimum parameter setting for each response factor, the additive model of Taguchi method was used. The analysis of variance for the factors is shown in table 5. It clearly indicates that the Toff is important for influencing MRR as compared to other parameters. In case of MRR, it is "Higher-the-better", so from this table it is concluded that Toff is the most influencing factor then Ton and current. Similarly analysis of variance for the factors is shown in table 7. It clearly indicates that the current (I) is important for influencing TWR as compared to other parameters. In case of TWR, it is "Lower-the-better", so from this table it is clear that current is the most influencing factor then Ton.

TABLE III. RESPONSE TABLE

\begin{tabular}{|c|c|c|c|c|c|c|c|c|}
\hline $\begin{array}{c}\text { Exp. } \\
\text { No. }\end{array}$ & $\begin{array}{c}T_{\text {on }} \\
(\mu \mathrm{S} \\
)\end{array}$ & $\begin{array}{l}T_{\text {off }} \\
(\mu \mathrm{s} \\
)\end{array}$ & $\begin{array}{l}\text { I } \\
\text { (A) }\end{array}$ & $\begin{array}{l}\text { ED } \\
(\mathbf{m m} \\
)\end{array}$ & $\begin{array}{c}\text { MRR } \\
(\mathbf{g m} / \mathbf{m i} \\
\text { n) }\end{array}$ & $\begin{array}{c}\text { TWR } \\
(\mathrm{gm} / \mathrm{mi} \\
\text { n) }\end{array}$ & $\begin{array}{l}\mathrm{S} / \mathrm{N} \\
\text { ratio } \\
\text { (MRR) }\end{array}$ & $\begin{array}{l}\text { S/N } \\
\text { ratio } \\
\text { (TWR) }\end{array}$ \\
\hline 1 & 3 & 4 & 8 & 6.23 & 0.0278 & $\begin{array}{c}0.0010 \\
7\end{array}$ & -33.9664 & 59.3539 \\
\hline 2 & 3 & 6 & 16 & 9.10 & 0.0854 & $\begin{array}{c}0.0039 \\
5\end{array}$ & -21.8215 & 48.0352 \\
\hline 3 & 3 & 9 & 24 & $\begin{array}{c}12.3 \\
0\end{array}$ & 0.4087 & $\begin{array}{c}0.0121 \\
2\end{array}$ & -8.5620 & 38.2491 \\
\hline 4 & 6 & 4 & 16 & $\begin{array}{c}12.3 \\
0\end{array}$ & 0.3141 & $\begin{array}{c}0.0091 \\
1\end{array}$ & -10.3528 & 40.7947 \\
\hline 5 & 6 & 6 & 24 & 6.23 & $\begin{array}{c}0.1014 \\
3\end{array}$ & $\begin{array}{c}0.0029 \\
9\end{array}$ & -19.8314 & 50.4748 \\
\hline 6 & 6 & 9 & 8 & 9.10 & 0.1403 & $\begin{array}{c}0.0077 \\
7\end{array}$ & -17.2389 & 42.1784 \\
\hline 7 & 9 & 4 & 24 & 9.10 & 0.1648 & $\begin{array}{c}0.0049 \\
0\end{array}$ & -15.2636 & 46.1814 \\
\hline 8 & 9 & 6 & 8 & $\begin{array}{c}12.3 \\
0\end{array}$ & 0.0412 & $\begin{array}{c}0.0011 \\
2\end{array}$ & -47.8230 & 58.8569 \\
\hline 9 & 9 & 9 & 16 & 6.23 & 0.0892 & $\begin{array}{c}0.0020 \\
0\end{array}$ & -24.3392 & 52.7134 \\
\hline
\end{tabular}

TABLE IV. RESPONSE TABLE OF S/N RATIO FOR MRR

\begin{tabular}{|l|l|l|l|l|}
\hline Level & Ton & Toff & I & ED \\
\hline 1 & -21.45 & -19.86 & -33.01 & -26.05 \\
\hline 2 & -15.81 & -29.83 & -18.84 & -18.11 \\
\hline 3 & -29.14 & -16.71 & -14.55 & -22.25 \\
\hline Delta & 13.33 & 13.11 & 18.46 & 7.94 \\
\hline Rank & 2 & 3 & 1 & 4 \\
\hline
\end{tabular}

TABLE V. ANNOVA TABLE FOR MRR

\begin{tabular}{|l|l|l|l|l|}
\hline Source & DF & Seq SS & Adj MS & P(\%Contribution) \\
\hline Ton & 2 & 268.80 & 134.40 & 23.31 \\
\hline Toff & 2 & 281.12 & 140.56 & 23.34 \\
\hline I & 2 & 559.86 & 279.93 & 46.48 \\
\hline ED & 2 & 94.57 & 47.28 & 7.85 \\
\hline Residual error & 0 & & & \\
\hline Total & 8 & 1204.35 & & 100.00 \\
\hline
\end{tabular}

TABLE VI. RESPONSE TABLE OF S/N RATIO FOR TWR

\begin{tabular}{|l|l|l|l|l|}
\hline Level & Ton & Toff & I & ED \\
\hline $\mathbf{1}$ & 48.55 & 48.78 & 53.46 & 54.18 \\
\hline $\mathbf{2}$ & 44.48 & 52.46 & 47.18 & 45.47 \\
\hline $\mathbf{3}$ & 52.58 & 44.38 & 44.97 & 45.97 \\
\hline Delta & 8.10 & 8.08 & 8.08 & 8.72 \\
\hline Rank & 3 & 4 & 2 & 1 \\
\hline
\end{tabular}

TABLE VII. ANOVA FOR TWR

\begin{tabular}{|l|l|l|l|l|}
\hline Source & DF & Seq SS & Adj MS & P (\% Contribution) \\
\hline Ton & 2 & 98.446 & 49.223 & 21.55 \\
\hline Toff & 2 & 98.074 & 49.037 & 21.47 \\
\hline I & 2 & 116.518 & 58.259 & 25.51 \\
\hline ED & 2 & 143.682 & 71.841 & 31.45 \\
\hline Error & 0 & & & \\
\hline Total & 8 & 456.720 & & 100.00 \\
\hline
\end{tabular}

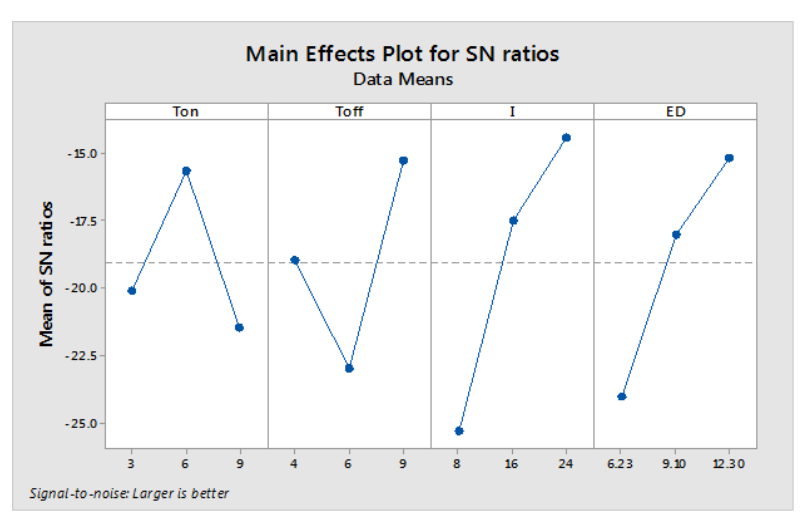

Fig. 1. Main effects plot for $\mathrm{S} / \mathrm{N}$ ratio of MRR

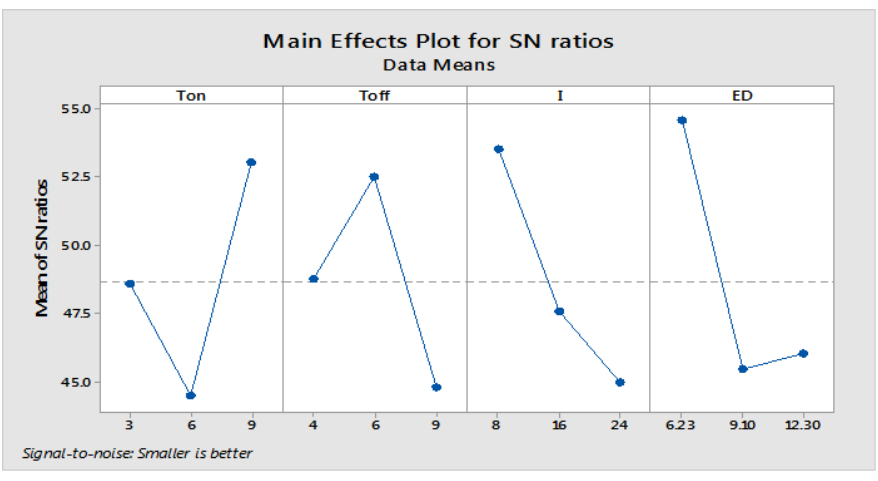

Fig. 2. Main effects plot for $\mathrm{S} / \mathrm{N}$ ratio of $\mathrm{TWR}$ 


\section{B. Verification experiment}

After performing statistical analysis on the experimental data, it was found that there is one paricular level foe each factor for which the performance measure (response) are either maximum (for MRR) or minmum (TWR) value. The signalto- noise ratio for each response corresponding to each factor level has a maximum and a minimum value. Therefore for finding optimum parameter setting for each response factors, the additive model of Taguchi method is used. S/N ratio should be always kept at maximum value. Input parameters levels are chosen in such a way that the $\mathrm{S} / \mathrm{N}$ ratio for that level has maximum value in order to obtain an optimum parameter setting for each response factor. There are four optimum parameters setting for all the two response factors. The combination of input factor levels, for which optimum setting is obtained is given in table 8 .

TABLE VIII. OPTIMAL PARAMETERS SETTING OF INPUT FACTOR

\begin{tabular}{|c|c|c|c|c|}
\hline \multirow{2}{*}{$\begin{array}{l}\text { Physical } \\
\text { requirement }\end{array}$} & \multicolumn{4}{|c|}{ Optimal combination } \\
\hline & $I(A)$ & Ton $(\mu s)$ & Toff $(\mu s)$ & $\overline{E D(\mathrm{~mm})}$ \\
\hline $\begin{array}{l}\text { Maximum } \\
\text { MRR }\end{array}$ & $\begin{array}{l}24 \\
\text { (LEVEL 3) }\end{array}$ & $\begin{array}{ll}6 & \text { (LEVEL } \\
\text { 2) } & \end{array}$ & $\begin{array}{ll}9 & \text { (LEVEL } \\
\text { 3) } & \end{array}$ & $\begin{array}{l}9.10 \\
\text { (LEVEL2) }\end{array}$ \\
\hline $\begin{array}{l}\text { Minimum } \\
\text { TWR }\end{array}$ & $\begin{array}{l}24 \\
\text { (LEVEL 3) }\end{array}$ & $\begin{array}{l}6 \text { (LEVEL } \\
\text { 2) }\end{array}$ & $\begin{array}{ll}9 & \text { (LEVEL } \\
\text { 3) } & \end{array}$ & $\begin{array}{l}9.10 \\
\text { (LEVEL2) }\end{array}$ \\
\hline
\end{tabular}

\section{TABLE IX. VERICATION EXPERIMENTS}

\begin{tabular}{|l|l|l|l|l|}
\hline \multirow{2}{*}{$\begin{array}{l}\text { Expt. } \\
\text { No. }\end{array}$} & \multicolumn{4}{|c|}{ MRR (gm/min.) } \\
\cline { 2 - 5 } & $\begin{array}{l}\text { Optimum } \\
\text { conditions }\end{array}$ & Expected & Predicted & Error \\
\hline 1. & A3B3C2D2 & 0.046025496 & 0.048611635 & $5.16 \%$ \\
\hline & \multicolumn{5}{|c}{ TWR (gm/min.) } \\
\hline 2. & A1B1C1D2 & 0.000295748 & 0.000313991 & $5.81 \%$ \\
\hline
\end{tabular}

\section{CONCLUSION}

In the present study, the effect of machining parameters on MRR and TWR of AISI 304 Stainless Steel component using copper tool have been investigated using EDM process. The experiments were conducted under various parameters setting of current (I), Pulse on time (Ton), Pulse off time (Toff) and Diameter of tool. L-9 OA based on Taguchi design was performed. Minitab software was used for analysis of the result and these responses were partially validated experimentally. The following conclusions are drawn from the analysis:

1. Pulse-on time (Ton) is most influencing factor then current (I) and electrode diameter for MRR. As the pulse duration extended, the MRR increases monotonically.

2. In case of TWR, the most important factor is current (I) then pulse-on time (Ton) and then electrode diameter (ED).
3. The optimal value for selected response variables MRR and TWR are $0.046025496 \mathrm{gm} / \mathrm{min}$. and $0.000295748 \mathrm{gm} / \mathrm{min}$. respectively.

4. The error between experimental and predicted values of MRR and TWR is found as $5.32 \%$ and $5.81 \%$ respectively.

\section{REFERENCES}

[1] J. Fleischer. J. Schmidt. S. Haupt, “"Combination of electric discharge machining and laser ablation in micro structuring of hardened steels," Microsyst Technol, Vol. 12: 2006; pp. 697-701.

[2] Non-conventional Machining, "Version 2 ME, IIT Kharagpur", PP(01- 04), http://nptel.iitm.ac.in /councellor.

[3] M. K. Pradhan, "Estimating the effect of process parameters on MRR, TWR and radial overcut of EDMed AISI D2 tool steel by RSM and GRA coupled with PCA" Int Adv Manuf Technol, DOI 10.1007/s00170-013-4780-9, (2013), pp-01.

[4] S. Singh, (2012), " Optimization of machining characteristics in electric discharge machining of $6061 \mathrm{Al} / \mathrm{Al} 2 \mathrm{O} 3 \mathrm{p} / 20 \mathrm{P}$ composites by grey relational analysis", Int J Adv Manuf Technol, 63: DOI 10.1007/s00170-012-3984-8, 2012, 1191-1202.

[5] G. Paul \& S. Roy \& S. Sarkar \& Naga Hanumaiah \& S. Mitra, ‘ "Investigations on influence of process variables on crater dimensions in micro-EDM of $\gamma$-titanium aluminide alloy in dry and oil dielectric media", Int J Adv Manuf Technol (2013) 65: DOI 10.1007/s00170012-4235-8, 2013, pp. 1009-1017.

[6] Payal, H.S., Choudhary, R., \& Singh, S., "Analysis Of electro discharged machined surfaces of EN31 tool steel", Journal Of scientific \& Industrial Research, Vol. 67, 2008, pp. 1072-1077.

[7] Pushpendra S. Bharti1, S. Maheshwari and C. Sharma, "Multiobjective optimization of electric-discharge machining process using controlled elitist NSGA-II, Journal of Mechanical Science and Technology 26 (6), 2012, pp. 1875 1883.

[8] Anirban Bhattacharya, Ajay Batish, and Naveen Kumar, "Surface characterization and material migration during surface modification of die steels with silicon, graphite and tungsten powder in EDM process", Journal of Mechanical Science and Technology, Vol. 27 (1), 2013, pp. 133 140.

[9] Renjie Ji \& Yonghong Liu \& Yanzhen Zhang \& Baoping Cai \& Jianmin Ma \& Xiaopeng Li , "Influence of dielectric and machining parameters on the process performance for electric discharge milling of SiC ceramic",. 'Int J Adv Manuf Technol, Vol. 59: DOI 10.1007/s00170-011-3493-1, 2012, pp. 127-136. 